\title{
Theoretical and Electrochemical Studies of the Coating Behavior of a New Epoxy Polymer: Hexaglycidyl Ethylene of Methylene Dianiline (HGEMDA) on E24 Steel in $3.5 \% \mathrm{NaCl}$
}

\author{
Rachid Hsissou ${ }^{a, *}$, Atiqa Bekhta ${ }^{a}$, Ahmed Elharfi ${ }^{a}$, \\ Bouchra Benzidia $^{b}$ and Najat Hajjaji ${ }^{b}$ \\ ${ }^{a}$ Laboratory of Agro Resources, Polymers and Process Engineering (LAPPE), Team of Organic \\ and Polymer Chemistry (TOCP), Department of Chemistry, Faculty of Sciences, Ibn Tofail \\ University, P.O. Box 133, 14000, Kenitra, Morocco \\ ${ }^{b}$ Laboratory of Materials, Electrochemistry and Environment, Team of Corrosion, Protection \\ and Environment, Department of Chemistry, Faculty of Sciences, Ibn Tofail University, P.O. \\ Box 133, 14000, Kenitra, Morocco
}

Received February 13, 2017; accepted September 18, 2017

\begin{abstract}
The objective of our work is to study, develop, characterize and apply a new epoxy macromolecular matrix in coatings, and their optimization for the conservation of marine heritage. Epoxy resins are technologically and nano-technologically compatible thermosetting macromolecule matrices that are easy to implement, according to their structures, viscosimetric and rheological properties, for the protection of the heritage possibly subject to atmospheric corrosion. In this sense, we have tested the new macromolecular binder, hexaglycidyl ethylene of methylene dianiline (HGEMDA), crosslinked and formulated for studying the behavior of steel coatings in a marine environment. In order to evaluate HGEMDA coating performance, we have studied its adsorption behavior onto the surface of corroded steel, and explained the interactions between the coating macromolecule and the steel surface. The coating effect on E24 steel was studied by quantum chemical calculations. The adsorption of HGEMDA onto the surface of E24 steel has been well described by the Quantitative Structure of Relation Property model (QSPR). The stationary and transient electrochemical studies are very interesting, since the prediction of the coating behavior was performed by the semi-empirical PM6, DFT methods and the method of three Becke compounds of parameter (UB3LYP), based on 6-311 G. All our calculations were performed using Gaussian software (03).
\end{abstract}

Keywords: HGEMDA, coating, crosslinking, formulation, E24 steel, QSPR, electrochemical studies and heritage.

\footnotetext{
* Corresponding author. E-mail address: r.hsissou@gmail.com
} 


\section{Introduction}

Epoxy polymers are very important technological thermosetting materials that have been widely used in several industrial fields, such as electronics [1, 2], coating [3], corrosion inhibition [4], packaging of radioactive wastes [5, 6], viscosimetric and rheological behavior [7,9]. They are also used as adhesives in aeronautical construction [10] and in space construction [11, 13]. The objective of our work is to develop a new coating for E24 steel, which is easy to implement, and inexpensive for the protection of the heritage subjected to standard atmospheric corrosion. The field of conservation/restoration uses some means of protection against corrosion, developed for industrial applications, among which are the so-called chemical or electrochemical conversion coatings, metallic deposits or organic polymer films, which are now commonly used. However, their use requires cleaning and preparing surfaces before application, which means the removal of corrosion products. As a result, these processes have been used in the field of heritage, for the protection of metal elements stored in the exterior. This research involves the physicochemical application and study of a new hexafunctional epoxy prepolymer, and its anticorrosive behavior towards E24 steel in the marine environment. These materials can be corroded in aggressive environments $[14,15]$, so, the best way to protect them against corrosion is to apply protective coatings [16, 17]. Among the various types of coatings, we find organic polymers which can play a very important role in the prevention of oxidation corrosion, thus avoiding the heritage degradation [18, 19].

The epoxy prepolymers coating method remains a very effective approach against accentuated and rapid corrosion, due to its good adhesion and acid/alkali resistance, and high crosslinking density [20], thanks to its macromolecular structure.

In this work, we have applied the new hexafunctional epoxy prepolymer: hexaglycidyl ethylene of methylene dianiline, synthesized in laboratory [21]. Evaluation of the coating impact by E1 (HGEMDA/MDA) and E2 (HGEMDA/MDA/PN) protective formulations on E24 steel was made by two electrochemical methods, namely stationary and transitory methods. The prediction of the coating behavior was carried out by semi-empirical equations [22, 23], molecular dynamics simulations [24, 25] and mathematical tools, including neural networks [26, 27], fuzzy sets [28] and graphs of theoretical indices $[29,30]$.

This led to the confirmation of the correlation of the molecular properties of this epoxy prepolymer (HGEMDA) with quantum chemistry calculations.

\section{Materials and methods \\ Hardware}

Products used

We have used several products among which are: the hexafunctional epoxide prepolymer, that is, hexaglycidyl ethylene of methylene dianiline (HGEMDA), 
synthesized in laboratory [21]; methylene dianiline; natural phosphate; and 3.5\% $\mathrm{NaCl}$. The latter products have been marketed by Aldrich Chemical Co.

\section{Electrochemical cell with three electrodes}

The electrochemical measurements were obtained by assembly of an electrochemical cell with three electrodes, as shown in Fig. 1.

A platinum electrode was used as counter electrode, a saturated calomel as reference electrode, and a cylindrical E24 steel as working electrode. The surface of contact with the corrosive solution was $1 \mathrm{~cm}^{2}$. Before each test, the working electrode was polished to an abrasive grade paper: 600, 1200 and 1500 .

These three electrodes were immersed in a $100 \mathrm{~mL}$ container, in which orifices of well-designed diameters and spacings were formed, enabling the introduction of the three electrodes, and also allowing systems of agitation, temperature control, aeration and deaeration.

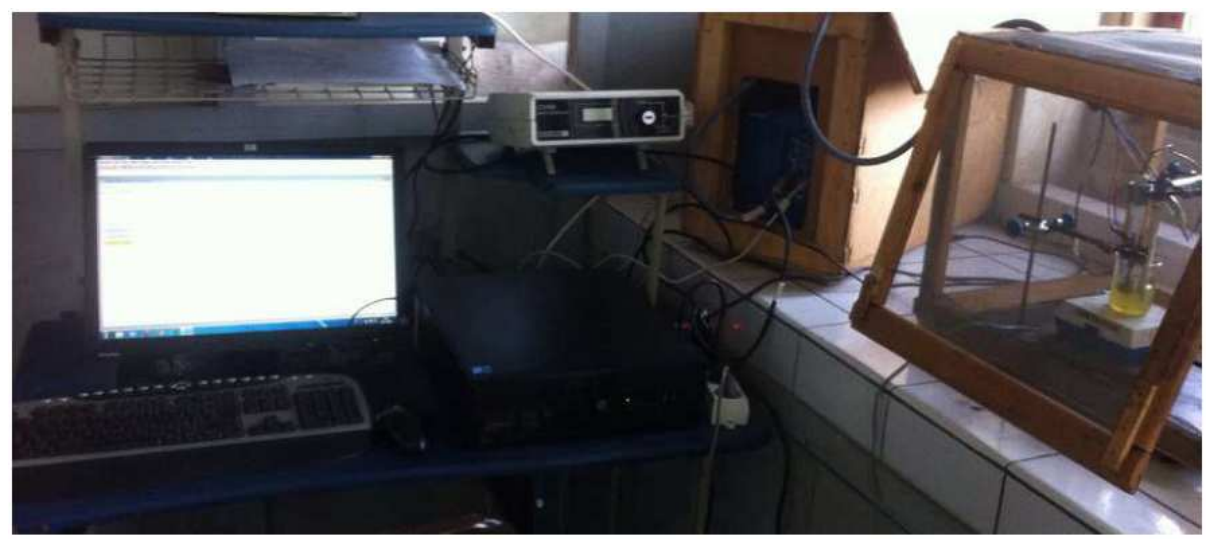

Figure 1. Three electrodes electrochemical cell.

\section{Electrochemical measurements}

The stationary measurements were carried out in a potentiodynamic mode by using a potentiostat/galvanostat SP-200 Biologic Science Instruments. The working electrode was previously kept immersed at the free corrosion potential for $30 \mathrm{~min}$. The scanning speed was $1 \mathrm{mV} / \mathrm{s}$. The determination of the electrochemical parameters $\left(i_{\text {corr }}, E_{\text {corr }}, \beta_{a}\right.$ and $\beta_{c}$ ) from the polarization curves was done by using a nonlinear regression by Ec-Lab software. Thus, the coating efficiency was calculated from the following formula:

$$
\eta \%=\left(\frac{i_{c o r r}^{0}-i_{\text {corr }}}{i_{\text {corr }}^{0}}\right) \times 100
$$

where $\mathrm{i}^{0}$ corr and $\mathrm{i}_{\text {corr }}$ are corrosion current densities $\left(\mathrm{A} . \mathrm{cm}^{-2}\right)$, respectively, with and without the coating polymer, in different formulations.

$\beta_{\mathrm{a}}$ and $\beta_{\mathrm{c}}$ are, respectively, the Tafel constants of the anodic and cathodic reactions $\left(\mathrm{V}^{-1}\right)$. These constants are related to the slope of Tafel $\beta\left(\mathrm{V} \cdot \mathrm{dec}^{-1}\right)$, and the form on the logarithmic scale is given by: 


$$
\beta=\frac{\ln (10)}{b}=\frac{2.303}{b}
$$

The measurements of the electrochemical impedance spectroscopy were carried out by using the same apparatus with a signal amplitude of $0 \mathrm{mV}$. The explored frequency range varied from $100 \mathrm{kHz}$ to $10 \mathrm{mHz}$. The efficiency of coating protection was evaluated by using the equation:

$$
\eta \%=\left(\frac{R_{p}-R_{p}^{0}}{R_{p}}\right) \times 100
$$

where $\mathrm{R}_{\mathrm{p}}^{\circ}$ and $\mathrm{R}_{\mathrm{p}}$ are, respectively, the polarization resistors in the absence and presence of the coating polymer with different formulations.

\section{The curing of hexaglycidyl ethylene from methylene dianiline}

We have used methylene dianiline as a hardener to crosslink the epoxy prepolymer, due to its high thermal stability and good mechanical properties towards the prepolymer. It is often used for high-tech applications with an implementation in the desired form. The chemical structure of methylene dianiline is shown in Fig. 2:<smiles>Nc1ccc(Cc2ccc(N)cc2)cc1</smiles>

Figure 2. Semi-developed formula of methylene dianiline.

\section{The ratio's calculation}

The stoichiometric coefficients' calculation

In order to obtain the optimum properties while curing a multifunctional epoxy resin with methylene dianiline, it is also desirable to make the resin and the curing agent react until approximately stoichiometric amounts [9]. This is the calculation of the epoxy equivalent weight (EEW) of the synthesized prepolymer (HGEMDA):

$$
E E W=\frac{M_{w}(H G E M D A)}{f}
$$

where $f$ is the epoxy resin's functionality.

Therefore:

$$
\begin{array}{r}
E E W=\frac{952}{6} \\
E E W=158.7 \mathrm{~g} / \mathrm{eq}
\end{array}
$$

The calculation of the AHEW (Amine Hydrogen Equivalent Weight) constitutes the mass of the hardener containing an amine equivalent. 


$$
A H E W=\frac{M_{w}(M D A)}{f}
$$

Methylene dianiline: $\mathrm{M}_{\mathrm{w}}=198 ; \mathrm{f}=4$

$$
\begin{gathered}
A H E W=\frac{198}{4} \\
A H E W=49.5
\end{gathered}
$$

Calculation of the ratio by weight

The hardener's ratio by weight, with regard to the resin, is calculated, in the majority of cases, by PHR (parts per hundred of resin):

$$
\operatorname{Amin}(\mathrm{PHR})=\frac{\text { AHEW }}{\text { equivalent epoxy }} \times 100
$$

In this case, HGEMDA:

$$
\begin{gathered}
\operatorname{Amin}(\mathrm{PHR})=(49.5 / 158.7) \times 100 \\
\text { Amin }(\mathrm{PHR})=31 \mathrm{~g} / \mathrm{eq}
\end{gathered}
$$

Therefore, it will be necessary to make $31 \mathrm{~g}$ of methylene dianiline per $100 \mathrm{~g}$ of HGEMDA, in order to reach the optimum properties when we cure the prepolymer with methylene dianiline.

The ratio to the weight of natural phosphate is calculated by the following equation:

$$
\mathrm{y} \%=\frac{\mathrm{x}}{\mathrm{resin}+\mathrm{MDA}+\mathrm{x}}
$$

where $\mathrm{x}$ is the quantity of HGEMDA resin and $\mathrm{y}$ is the amount of the natural phosphate charge.

\section{The coating of E24 steel by HGEMDA}

The metallic material was cut into plates of $1 \mathrm{~cm}^{2}$. In order to obtain reliable and reproducible results before each test, the surface of the plates was polished with abrasive paper of increasing fine granulometry (600, 1200 and 1500), before being soaked in the corrosive solution; then, it was rinsed with distilled water and finally dried in the air. The used experimental protocol was as follows:

Formulation 1 (HGEMDA/MDA): we have mixed $1 \mathrm{~g}$ of HGEMDA with $0.30 \mathrm{~g}$ of MDA as hardener, stirred the mixture, and then we left it for about 30 min to homogenize it. The formulation was applied to E24 steel by using a filmproducing rod. This coated plate was placed in an oven for 24 hours at $70{ }^{\circ} \mathrm{C}$, to crosslink the polymer deposited on the substrate.

Formulation 2 (HGEMDA/MDA/PN): we have followed the previous protocol (formulation 1) with the addition of $5 \%$ of natural phosphate as filler. 


\section{Methodology for calculating the parameters of quantum chemistry}

The quantum chemistry calculations have been widely used to study the reactions mechanisms [31]. They also proved to be a very interesting tool in studying the molecules properties $[32,33]$. The physical properties have shown to be related to the molecular structure and spatial electronics.

In this research, we have studied the relationship between quantum chemistry parameters and the epoxy prepolymer coating behavior. The quantum chemical parameters were calculated by the semi-empirical method of the neutral macromolecular matrix, negatively and positively charged, i.e., the parametric method (PM6 and DFT) and the three Becke compounds method (UB3LYP) were thus used on the basis of 6-311G. All these calculations were performed by Gaussian software (03).

The calculated quantum chemical parameters are the energy of the highest occupied molecular orbital $\left(\mathrm{E}_{\mathrm{HOMO}}\right)$ and the energy of the lowest unoccupied molecular orbital (ELUMO). These molecular orbitals ( $E_{\text {HOMO }}$ and $E_{\text {LUMO }}$ ) of the coating molecule are linked to the ionization energy (I) and to the electronic affinity $(\mathrm{A})$, respectively, $\mathrm{I}=-\mathrm{E}_{\mathrm{HOM}}$ and $\mathrm{A}=-\mathrm{E}_{\mathrm{LumO}}$. Gap energy $\left(\Delta \mathrm{E}=\mathrm{E}_{\mathrm{LUMO}}-\right.$ $\left.\mathrm{E}_{\mathrm{HOMO}}\right)$, softness $(\sigma)$, ionization potential $(\mathrm{Pi})$, electronegativity $(\chi)$, absolute hardness $(\eta)$, function of the transferred electrons at the surface of the metal $(\Delta N)$ and the electrophilic character, $\omega$, are all related, according to Koopmans theorem [34].

The ionization potential $(\mathrm{Pi})$ of the coating behavior is calculated using the following equation:

$$
\mathrm{P}_{\mathrm{i}}=\frac{\mathrm{E}_{\mathrm{HOMO}}+\mathrm{E}_{\mathrm{LUMO}}}{2}
$$

Electronegativity $(\chi)$ and absolute chemical hardness $(\eta)$ can be evaluated by using the following equations [35]:

$$
\begin{aligned}
& \chi= P_{i} \\
& \eta=\frac{\Delta E}{2}=\frac{E_{\text {LUMO }}-E_{\text {HOMO }}}{2}
\end{aligned}
$$

The chemical softness $(\sigma)$, which describes the ability of an atom or a group of atoms to accept electrons, is calculated according to the following equation [36]:

$$
\sigma=\frac{1}{\eta}=\frac{2}{E_{\text {номо }}-E_{\text {LUмо }}}
$$

The number of transferred electrons $(\Delta \mathrm{N})$ was calculated according to the chemical quantum method by the following equation [37]:

$$
\Delta N=\frac{\chi_{F e}-\chi_{\text {int }}}{2\left(\eta_{F e}+\eta_{\text {int }}\right)}
$$

The electrophilic character, $\omega$, is a reactivity descriptor that allows a quantitative classification of the electrophilic nature of a compound within a relative scale. 
We proposed $\omega$ as a measure of maximum energy lowering, due to the electrons transport between the donor and the acceptor flow. $\omega$ is defined by the following relationship [38]:

$$
\omega=\frac{\chi^{2}}{2 \eta}
$$

The constituents of E24 steel are grouped in Table 1.

Table 1. Different constituents of E24 steel.

\begin{tabular}{cccccc}
\hline Constituents & Carbon & Manganese & Phosphorous & Sulfur & Others \\
\hline Percentage $(\%)$ & 0.19 & 0.75 & 0.045 & 0.045 & 0.02 \\
\hline
\end{tabular}

Manganese is the major compound in E24 steel, so we have taken its electronegativity for the calculation of the number of transferred electrons $(\Delta N)$. $\chi_{\mathrm{Mn}}$ and $\chi_{\text {inh }}$ represent the absolute electronegativity of manganese and the coating molecule, and $\eta_{\mathrm{Mn}}$ and $\eta_{\text {inh }}$ denote, respectively, the absolute hardness of manganese and the coating molecule. In this study, we have used the theoretical values of $\chi_{\mathrm{Mn}}=1.55$ and $\eta_{\mathrm{Mn}}=6$, for the calculation of the number of transferred electrons.

The local reactivity was performed at the level of Fukui indices. This study indicates the region of an atom or a series of atoms' reactivity, which is responsible for the nucleophilic and electrophilic attacks of each of these atoms in the tested molecule.



Figure 3. Polarization curves of $\mathrm{E} 24$ steel in $3.5 \% \mathrm{NaCl}$, in the presence of the matrices $\left(\mathrm{E}_{0}, \mathrm{E}_{1}\right.$ and $\left.\mathrm{E}_{2}\right)$ after $30 \mathrm{~min}$ of immersion at $298 \mathrm{~K}$.

\section{Results and discussions}

\section{Polarization curves}

Fig. 3 shows the potentiodynamic polarization curves that describe the protective effect of $E 24$ steel in a marine environment, $E_{0}$, by the formulations $E_{1}$ (HGEMDA/MDA) and $\mathrm{E}_{2}$ (HGEMDA/MDA/PN).

The electrochemical parameters of $E_{1}$ (HGEMDA/MDA) and $E_{2}$ (HGEMDA/MDA/PN) coating matrices are summarized in Table 2. 
Table 2. The various electrochemical parameters taken from polarization curves.

\begin{tabular}{lcccccc}
\hline \multicolumn{1}{c}{ Protective matrices } & $\begin{array}{c}\text { Plaques } \\
(\mathbf{E i})\end{array}$ & $\begin{array}{c}-\mathbf{E}_{\mathbf{c o r r}} \\
(\mathbf{m V} / \mathbf{A g} / \mathbf{A g C l})\end{array}$ & $\begin{array}{c}\mathbf{I}_{\mathbf{c o r r}} \\
\left(\boldsymbol{\mu} \mathbf{A} / \mathbf{c m}^{2}\right)\end{array}$ & $\begin{array}{c}\beta_{\mathbf{c}} \\
(\mathbf{m V} / \mathbf{d e c})\end{array}$ & $\begin{array}{c}\beta_{\mathbf{a}} \\
(\mathbf{m V} / \mathbf{d e c})\end{array}$ & $\begin{array}{c}\boldsymbol{\eta} \\
(\boldsymbol{\%})\end{array}$ \\
$\mathrm{NaCl} 3.5 \%$ & $\mathrm{E}_{0}$ & 658 & 42.5 & 453 & 129 & - \\
HGEMDA/MDA & $\mathrm{E}_{1}$ & 620 & 2.5 & 130 & 138 & 94 \\
HGEMDA/MDA/PN & $\mathrm{E}_{2}$ & 607 & 1.94 & 150 & 177 & 96.5 \\
\hline
\end{tabular}

The study of these curves has enabled us to make the following observations: the cathodic branches show no linearity, and are considered as the sum of the two curves (show mixed kinetics) by oxygen reduction and hydrogen evolution [39]. However, the anodic branches also do not exhibit any linearity due to E24 steel dissolution [40].

The protective mechanism herein studied, according to the protective matrices $\left(\mathrm{E}_{0}, \mathrm{E}_{1}\right.$ and $\left.\mathrm{E}_{2}\right)$, was constituted by the standard polymeric epoxy resin (HGEMDA), the hardener (MDA) and the charge formed by the natural phosphate layer. The interpretation of the results, according to the constitution of the matrix, is given as follows.

In the $\mathrm{E}_{0}$ matrix, without substrate coating, as a control, the anions $\mathrm{Cl}^{-}$and $\mathrm{OH}^{-}$, coming from a corrosive medium, directly attack the substrate, which induces a direct and increased corrosion.

Fig. 4 and 5, respectively, show the protection mechanism of E24 steel by $E_{1}$ (HGEMDA/MDA) and $\mathrm{E}_{2}$ (HGEMDA/MDA/PN) formulations, with and without natural phosphate.

Through the $\mathrm{E}_{1}$ (HGEMDA/MDA) matrix, we have anticipated that there would be a relatively large diffusion of chloride and hydroxide ions through the protective film, which could exhibit micropores, by inducing the primary corrosion translated by $\mathrm{i}_{\text {corr }}=2.5 \mu \mathrm{A} / \mathrm{cm}^{2}$ and $\eta \%=94 \%$. This would lead to an acceleration of the metal anodic dissolution [41].

Once applied the $\mathrm{E}_{2}$ matrix (HGEMDA/MDA/PN), we observe the formation of the material's oxide, which acts as a protective layer of short duration $[42,43]$. In this case, the electrochemical corrosion parameters are $\mathrm{i}_{\text {corr }}=1.94 \mu \mathrm{A} / \mathrm{cm}^{2}$ and $\Pi$ $=96.5 \%$.

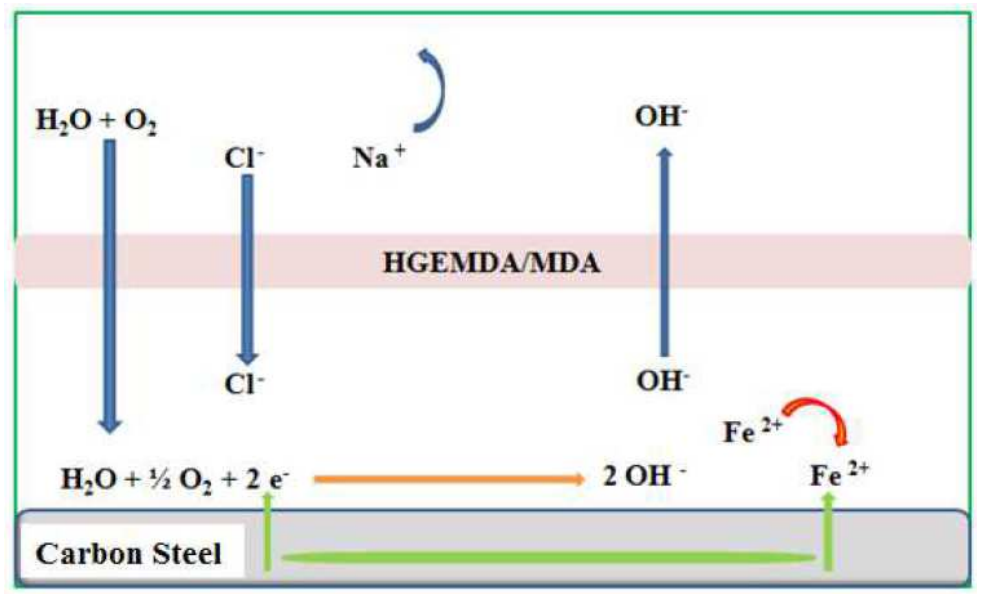

Figure 4. Mechanism of the $E_{1}$ protective matrix (HGEMDA/MDA), amid the metal substrate and the film, after immersion in $3.5 \% \mathrm{NaCl}$. 


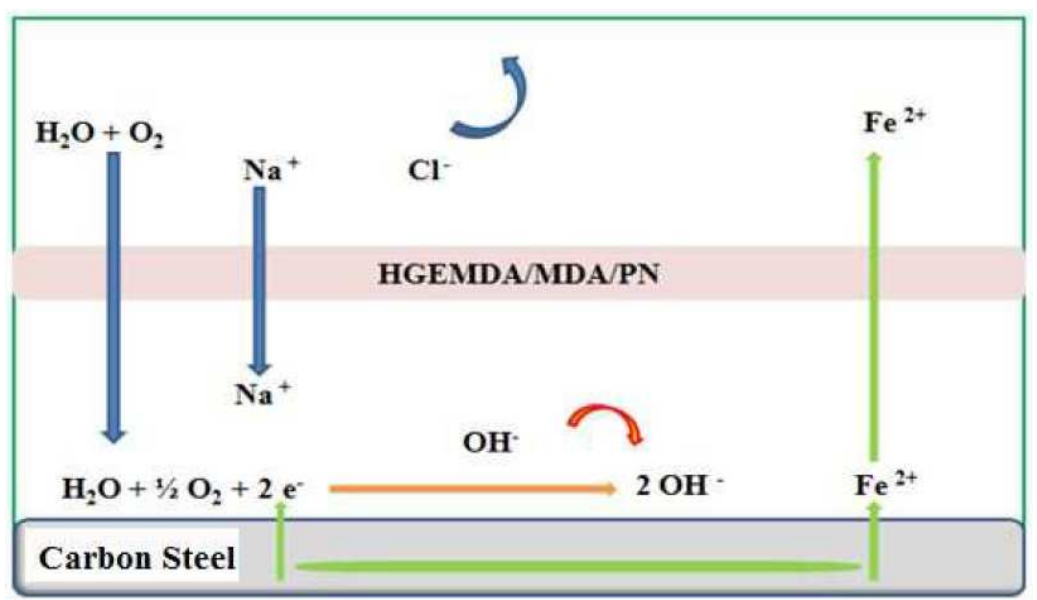

Figure 5. Mechanism of the $\mathrm{E}_{2}$ protective matrix (HGEMDA/MDA/PN), amid the metal substrate and the film, after immersion in $3.5 \% \mathrm{NaCl}$.

The addition of $5 \%$ of natural phosphate is accompanied by a marked decrease in the corrosion current, in both cathodic and anodic domains.

The corrosion potential moves overall towards the anode direction, after the addition of $\mathrm{E}_{1}$ (HGEMDA/MDA) and $\mathrm{E}_{2}$ (HGEMDA/MDA/PN). This allowed us to conclude that natural phosphate added to the formulation acts as a mixed inhibitor.

\section{Electrochemical impedance spectroscopy}

In order to confirm the results obtained by the potentiodynamic polarization curves, and to study the coating behavior mechanism in more details, electrochemical impedance spectroscopy was performed. The results of this method are represented in the form of Nyquist diagrams. These impedance diagrams of E24 steel immersed 30 min before each open circuit measurement in the corrosive $3.5 \% \mathrm{NaCl}$ solution, with respect to the set of matrices $\left(\mathrm{E}_{0}, \mathrm{E}_{1}\right.$ and $\left.E_{2}\right)$, are presented in Fig. 6.

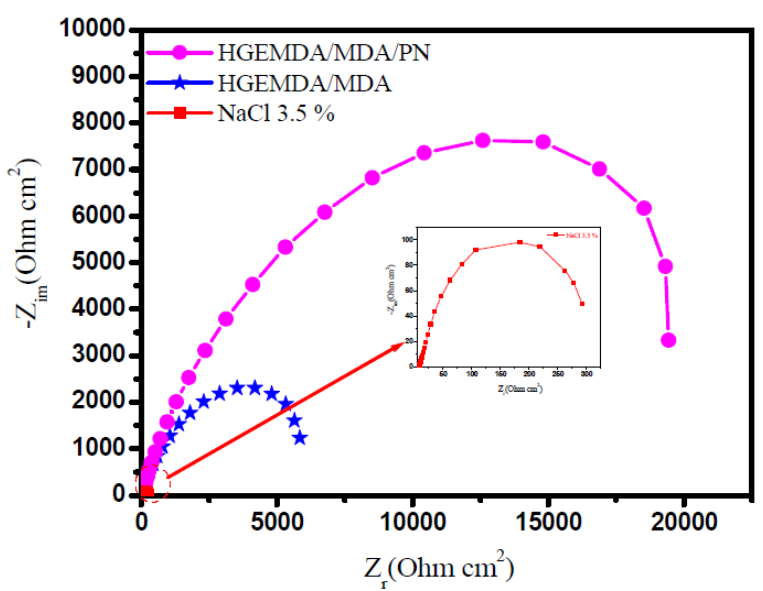

Figure 6. Open-circuit electrochemical impedance diagrams after immersing E24 steel in $3.5 \% \mathrm{NaCl}$, in the presence of the matrices $\left(\mathrm{E}_{0}, \mathrm{E}_{1}\right.$ and $\left.\mathrm{E}_{2}\right)$ at $298 \mathrm{~K}$.

The analysis of the different diagrams composing, respectively, the protective matrices $E_{0}, E_{1}$ and $E_{2}$ shows that the latter is formed by a high-frequency 
capacitive loop attributed to the film effect, which is due to the diffusion phenomenon. Indeed, the more the semicircle diameter increases, the better the corrosion resistance of the protective film is [44]. This study would confirm the results obtained by the stationary method.

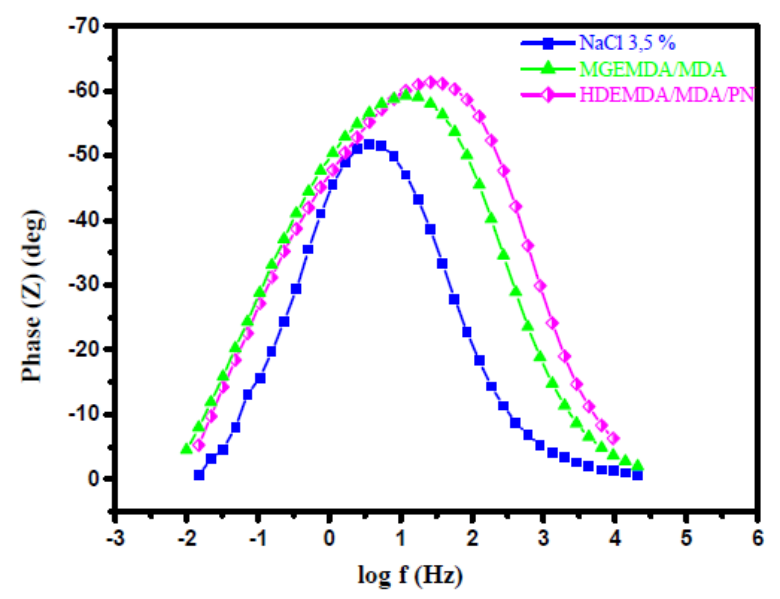

Figure 7. HGEMDA phase angle diagrams in $3.5 \% \mathrm{NaCl}$, after $30 \mathrm{~min}$ immersion with different formulations $\left(\mathrm{E}_{0}, \mathrm{E}_{1}\right.$ and $\left.\mathrm{E}_{2}\right)$ at $298 \mathrm{~K}$.

Fig. 7 and 8, respectively, show the diagrams of Bode and phase angle of E24 steel coating behavior in a marine environment. The plots of these diagrams in the presence of different formulations $\left(\mathrm{E}_{0}, \mathrm{E}_{1}\right.$ and $\left.\mathrm{E}_{2}\right)$ are illustrated in the figures below. In Fig. 7, we have found that the phase angles increased with an increasing coating formulation. This increase in the phase angles confirms a higher protection by the increase in the coating formulation $\left(\mathrm{E}_{0}, \mathrm{E}_{1}\right.$ and $\left.\mathrm{E}_{2}\right)$. Indeed, from this phase angle diagram, we have found that there are three frequency domains: low frequencies, high frequencies and intermediate frequencies.

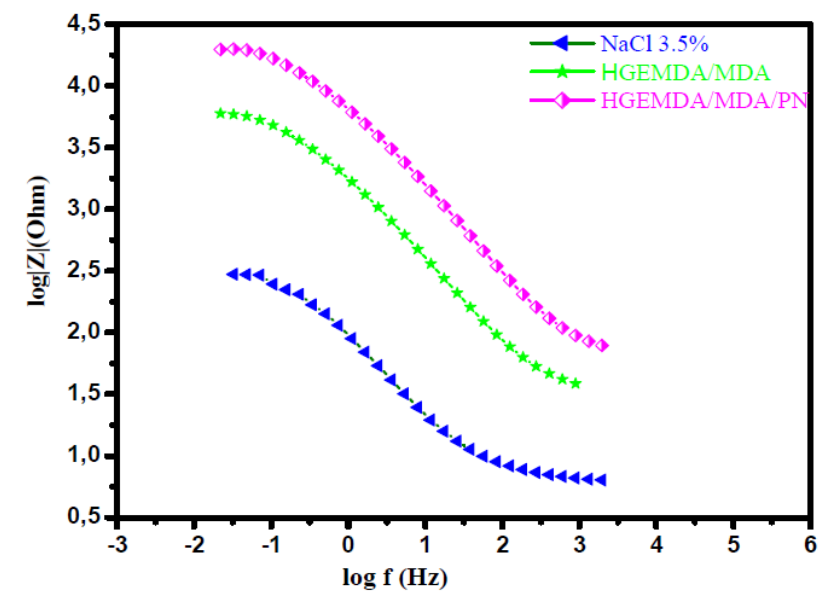

Figure 8. HGEMDA Bode patterns in $3.5 \% \mathrm{NaCl}$, after 30 min immersion with various formulations $\left(\mathrm{E}_{0}, \mathrm{E}_{1}\right.$ and $\left.\mathrm{E}_{2}\right)$ at $298 \mathrm{~K}$.

For low frequencies, the increase in the absolute impedance values confirms the greatest protection with the different coating formulations on E24 steel (Fig. 8). At high frequency, the phase angle values are approximately equal to zero, which 
indicates that the electrode behavior corresponds to the solution resistance [45]. In the intermediate frequencies, the phase angle is close to $70^{\circ}$, and a linear relation between $\log |\mathrm{Z}|$ in view of $\log (\mathrm{f})$ with a slope close to -1 was observed, which indicates the coating capacitive behavior at intermediate frequencies.

The capacitor behavior, according to the literature, would be ideal if the slope value reached -1 , and if a phase angle value reached $90^{\circ}$. The phase angle values are calculated through the phase curves ( $Z$ ) in view of $\log$ (frequency). These values of $\alpha$ vary between -0.50 and -0.70 for the different coating formulations, which could be related to the non ideal structure of the metal/solution interface. These results confirm those of the electrochemical impedance spectroscopy.

From the curve shapes presented in the Bode and Nyquist diagrams, the latter shows an interface capacitive behavior, and the existence of an equivalent electrical circuit (Fig. 9) that contains a constant phase element unique in the metal/solution interface in all the examined frequencies. This is due to the interpretation of the information related to the coating behavior properties or to the metal surface corrosion. This circuit is composed of $R_{s}$ (electrolyte's resistance), $C_{f}$ (coating film capacity), $R_{f}$ (coating film resistance), $R_{c t}$ (load transfer resistor) and $\mathrm{C}_{\mathrm{dl}}$ (double layer capacity).

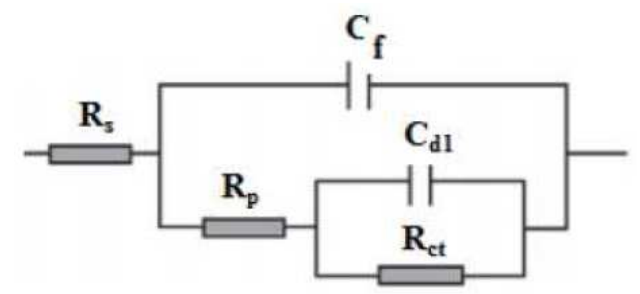

Figure 9. Equivalent electrical circuit proposed for the adjustment of the impedance spectra obtained in the presence of different formulations on E24 steel in 3.5\% $\mathrm{NaCl}$.

The electrochemical impedance values and the efficiency resulting from each protection matrix $\left(\mathrm{E}_{0}, \mathrm{E}_{1}\right.$ and $\left.\mathrm{E}_{2}\right)$ are grouped in Table 3.

Table 3. Various electrochemical parameters taken from the impedance diagrams.

\begin{tabular}{ccccccc}
\hline $\begin{array}{c}\text { Protective matrices } \\
\mathbf{E}_{\mathbf{i}}\end{array}$ & $\begin{array}{c}\mathbf{R}_{\mathbf{s}} \\
\left(\boldsymbol{\Omega . c m} \mathbf{c m}^{2}\right)\end{array}$ & $\begin{array}{c}\mathbf{R}_{\mathbf{c t}} \\
\left(\mathbf{\Omega . c m}^{\mathbf{2}}\right)\end{array}$ & $\begin{array}{c}\mathbf{C}_{\mathbf{d l}} \\
\left(\boldsymbol{\mu} \mathbf{F} / \mathbf{c m}^{2}\right)\end{array}$ & $\begin{array}{c}\mathbf{C}_{\mathbf{f}} \\
\left(\boldsymbol{\mu} \mathbf{F} / \mathbf{c m}^{2}\right)\end{array}$ & $\begin{array}{c}\mathbf{R}_{\mathbf{p}} \\
\left(\mathbf{\Omega . c m}^{2}\right)\end{array}$ & $\begin{array}{c}\mathbf{\eta} \\
(\boldsymbol{\%})\end{array}$ \\
$\mathrm{E}_{0}$ & 6.5 & 2.40 & 1253 & 935 & 218.6 & - \\
$\mathrm{E}_{1}$ & 30.98 & 5.72 & 136.6 & 5.96 & 7374 & 97 \\
$\mathrm{E}_{2}$ & 62.22 & 13.6 & 37.24 & 1.93 & 25595 & 99 \\
\hline
\end{tabular}

This table shows that the coating film resistance values for the coating behavior matrices are confirmed through the parameters results from the potentiodynamic polarization curves. Table 4 summarizes the results of the stationary and transient methods.

The coating behavior is correlated with a very low barrier effect, due to the existence of pores and defects in the coating and/or poor adhesion amid the coating and the metal substrate. The absence of adhesion of the unpigmented coatings is suggested by the obtained low charge transfer resistance and the rapid formation of bubbles over the entire coating surface, in which a significant corrosion occurs [46]. On this basis, the largest semi-circle in the $\mathrm{E}_{2}$ coating 
system Nyquist diagram indicates a better corrosion resistance (see Table 4). This can be explained by the presence of natural phosphate, which is responsible for the higher corrosion resistance.

Table 4. Evaluation parameters of the stationary and transient method.

\begin{tabular}{ccccc}
\hline & \multicolumn{2}{c}{ Stationary method } & \multicolumn{2}{c}{ Transient method } \\
$\mathrm{E}_{\mathrm{i}}$ & $\begin{array}{c}\mathrm{I}_{\text {corr }} \\
\left(\mu \mathrm{A} / \mathrm{cm}^{2}\right)\end{array}$ & $(\%)$ & $\begin{array}{c}\mathrm{R}_{\mathrm{p}} \\
\left(\Omega . \mathrm{cm}^{2}\right)\end{array}$ & $(\%)$ \\
$\mathrm{E}_{0}$ & 42.5 & - & 218.6 & - \\
$\mathrm{E}_{1}$ & 2.5 & 94 & 7374 & 97 \\
$\mathrm{E}_{2}$ & 1.94 & 96.5 & 25595 & 99 \\
\hline
\end{tabular}

\section{Modelization}

The experimental results concerning E24 steel coating behavior in a marine environment were simultaneously obtained through the potentiodynamic/stationary method and the Nyquist mode/transient method. This showed that the metal protection efficiency, by the different formulations of $\mathrm{E}_{1}$ and $E_{2}$ from the macromolecular structure of the new synthesized epoxy hexaglycidyl ethylene of methylene dianiline (HGEMDA), is very good, since it is equal, respectively, to $\eta_{\mathrm{s}}\left(\mathrm{E}_{1}\right)=94 \%$ and $\eta_{\mathrm{s}}\left(\mathrm{E}_{2}\right)=96.5 \%$; and $\eta_{\mathrm{t}}\left(\mathrm{E}_{1}\right)=97 \%$ and $\div \eta \mathrm{t}\left(\mathrm{E}_{2}\right)=99 \%$.

In order to confirm the adhesion sites of the epoxy polymer, which are responsible for the experimental results (reflecting the good adherence of our epoxy hexafunctional macromolecular matrix [20] composed of six aromatic nuclei on the one hand, and an ethylenic nucleus on the other hand) we have carried out the calculation study of quantum chemistry through Gaussian software (03).

To perform the calculation of the quantum chemistry parameters of the epoxy resin, several descriptors were studied on the electronic steric basis and the thermodynamic effect.

The calculation of the different descriptors was carried out by two different methods: the first one was semi-empirical (PM6), and a second one was based on the electron density (DFT) through Gaussian software (03). The main results of this study are summarized in Table 5.

Table 5. Parameters of quantum chemistry calculations of the various descriptors.

\begin{tabular}{crcrrrr}
\hline & \multicolumn{2}{c}{ DFT } & \multicolumn{2}{c}{ HGEMDA } & \multicolumn{2}{c}{ PM6 } \\
& \multicolumn{1}{c}{0} & \multicolumn{1}{c}{-1} & \multicolumn{1}{c}{0} & -1 & 1 \\
$\mathrm{E}_{\text {HOMO }}(\mathrm{eV})$ & -0.238 & -0.170 & -0.269 & -0.266 & -0.167 & -0.269 \\
$\mathrm{E}_{\mathrm{LUMO}}(\mathrm{eV})$ & -0.170 & -0.168 & -0.238 & -0.169 & -0.166 & -0.170 \\
$\mathrm{I}(\mathrm{eV})$ & 0.238 & 0.170 & 0.269 & 0.266 & 0.167 & 0.269 \\
$\mathrm{~A}(\mathrm{eV})$ & 0.170 & 0.168 & 0.238 & 0.169 & 0.166 & 0.170 \\
$\Delta \mathrm{E}(\mathrm{eV})$ & 0.068 & 0.001 & 0.031 & 0.097 & 0.001 & 0.099 \\
$\mathrm{P}_{\mathrm{i}}$ & -0.204 & -0.169 & -0.254 & -0.217 & -0.167 & -0.220 \\
$\chi$ & 0.204 & 0.169 & 0.254 & 0.217 & 0.167 & 0.220 \\
$\eta$ & 0.034 & 0.0008 & 0.015 & 0.048 & 0.0005 & 0.049 \\
$\sigma$ & 29.133 & 1183.430 & 64.246 & 20.614 & 1724.137 & 20.044 \\
$\omega$ & 0.609 & 16.971 & 2.079 & 0.488 & 24.076 & 0.4854 \\
$\Delta \mathrm{N}$ & 0.111 & 0.115 & 0.107 & 0.110 & 0.115 & 0.109 \\
\hline
\end{tabular}


In order to better understand the coating behavior adsorption mechanism studied on the surface of E24 steel, optimization analysis to estimate active coating adsorption centers was made, and quantum chemical calculations were performed. This was precisely done by the PM6 and DFT methods, the optimized geometrical structures and the $\mathrm{E}_{\mathrm{HOMO}}$ and $\mathrm{E}_{\mathrm{LUMO}}$ electron density distributions. These coatings are presented in Fig. 10-15. The quantum chemical parameters were calculated and analyzed, in order to explain the reactivity of the electropositive and electronegative sites of the HGEMDA molecule. These are grouped in Table 5. The high ionization energy indicates a high stability [47, 48]; $\Delta \mathrm{N}<3.6$ indicates the tendency of a molecule to give electrons to the metal surface $[49,50]$.

The $\mathrm{E}_{\text {Hомо }}$ and $\mathrm{E}_{\mathrm{Lumo}}$ of the orbital of the neutral, positively and negatively charged macromolecular matrices of the two studied methods are respectively shown in the figures below. This clearly shows that the electronic effect reacts with the coating behavior phenomenon on the aromatic system, epoxy group and ethylenic kernel.
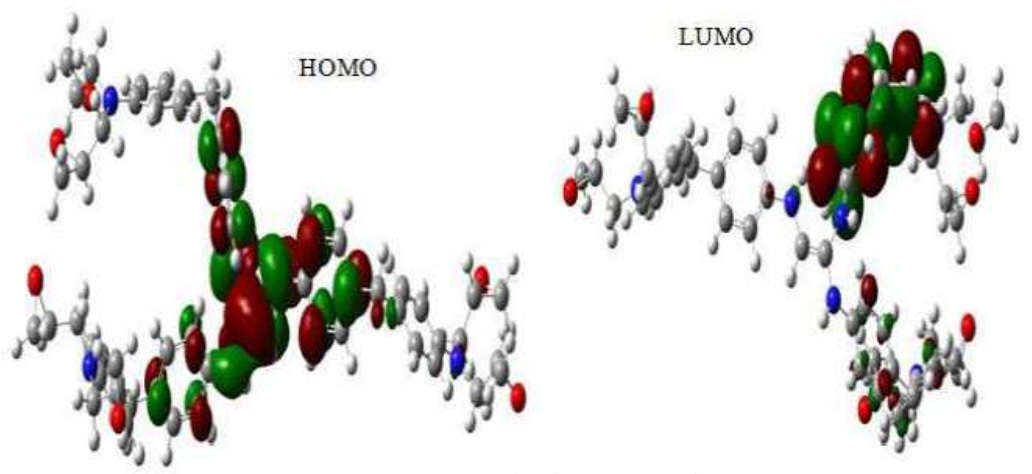

Figure 10. PM6 method of the neutral HGEMDA.

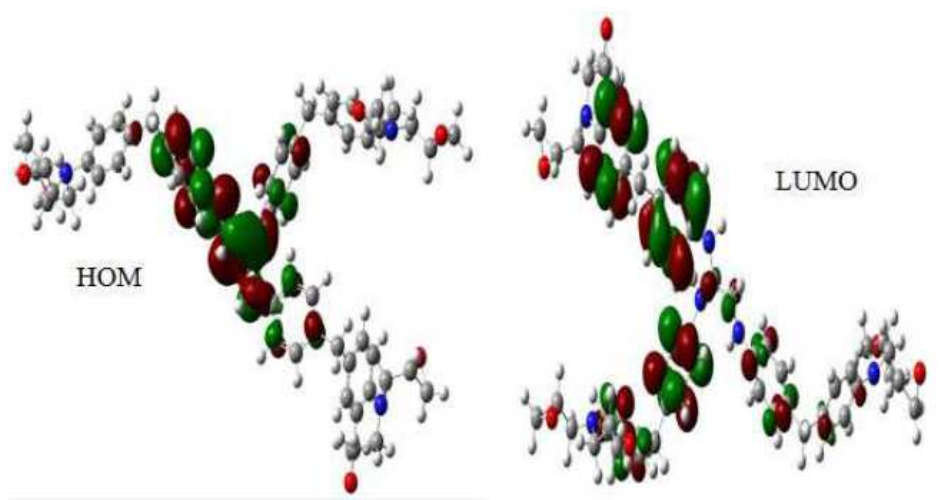

Figure 11. PM6 method of negatively charged HGEMDA. 


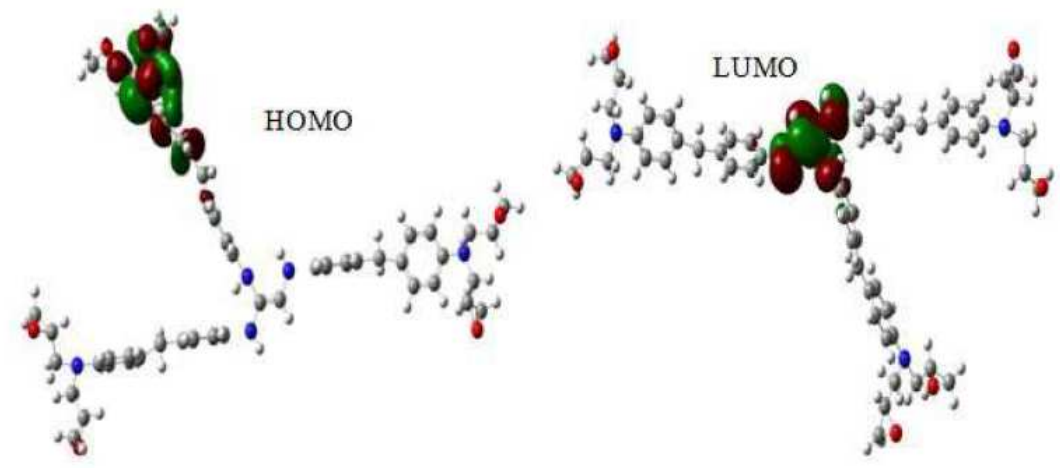

Figure 12. PM6 method of positively charged HGEMDA.
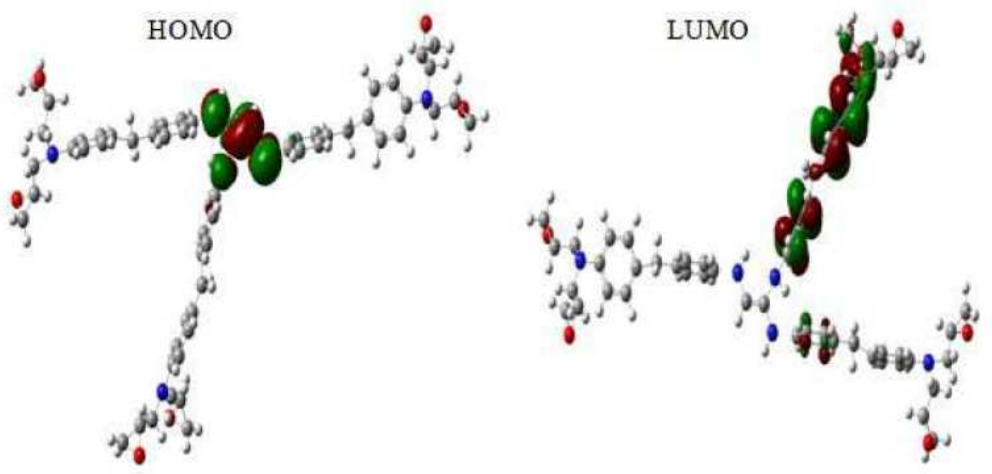

Figure 13. DFT method of the neutral HGEMDA.
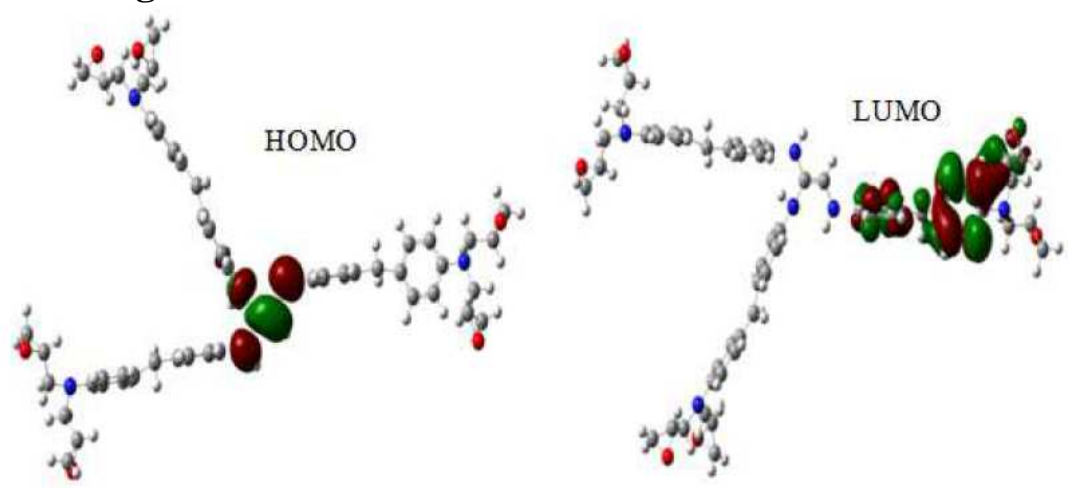

Figure 14. DFT method of negatively charged HGEMDA.

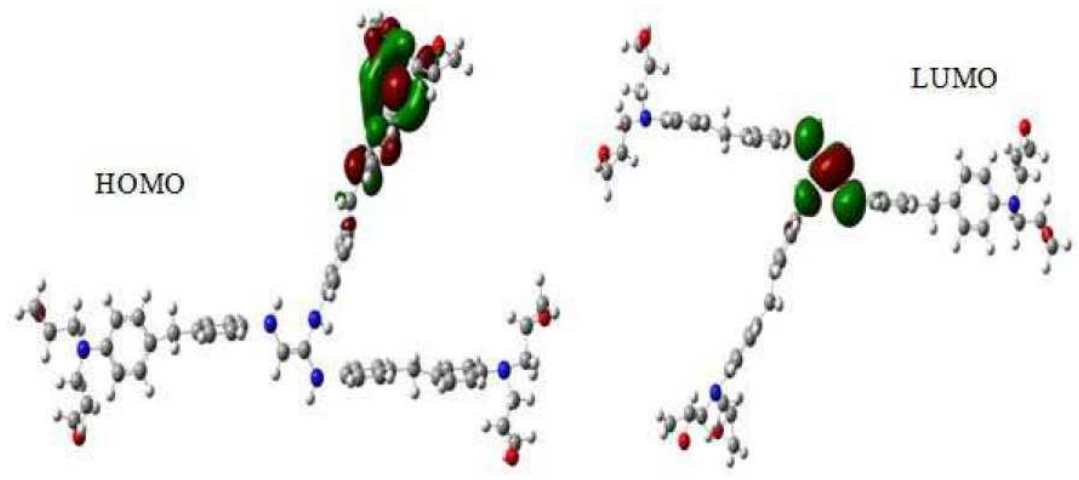

Figure 15. DFT method of the positively charged HGEMDA.

Eномо generally describes the ability of a compound to give electrons. A high energy value of the HOMO energy orbital facilitates the tendency of molecules to yield electrons to acceptable electron species with unoccupied molecular 
orbitals that have low energy levels. On the other hand, ELumo is related to the ability of a molecule to accept electrons. A low value of LUMO energy means that the molecule certainly accepts electrons. Thus, the adsorption of energy amid the coating behavior and the metal surface of E24 steel increases when the gap energy $\left(\Delta \mathrm{E}=\mathrm{E}_{\text {LumO }}-\mathrm{E}_{\text {HOMO }}\right)$ decreases [51]. From the analysis in Table 5, we have observed that the gap energy values are lower between the molecular orbital boundaries of the donor and the acceptor. This indicates that the quality of the film formation is good. With respect to the donor and the electron acceptor molecular orbitals, we have observed in the figures above that the electron densities (HOMO) are localized, respectively: on the aromatic cycle surface, on the ethylenic nucleus for the PM6 method (neutral and negatively charged), on the ethylenic nucleus surface for the DFT (neutral and negatively charged) method, and on the surface of the epoxy group and the aromatic cycle for both PM6 and DFT (positively charged) methods. On the other hand, the electronic densities (LUMO) are located on the aromatic cycle surface for the two PM6 and DFT methods (neutral and negatively charged), and on the surface of the ethylenic nucleus for the two PM6 and DFT (positively charged) methods.

The results indicate that the adsorption efficiency of the coating behavior increases with the ionization potential $(\mathrm{Pi})$, because this property is directly related to Еномо. In other words, the adsorption of the coating behavior or the adhesion of the epoxy macromolecular resin onto the metal support take place at the level of the aromatic cycles, epoxide cycles and the ethylenic radical, with respect to the micro-gaps on the substrate surface.

\section{Conclusion}

In this work, we have tested the new synthesized hexafunctional epoxy prepolymer, hexaglycidyl ethylene of methylene dianiline, in the protection of E24 steel by the coating behavior process derived from the formulations based on standard epoxy prepolymer, methylene dianiline and natural phosphate used as a charge. The obtained electrochemical results, namely the potentiodynamic polarization curves and those of the electrochemical impedance spectroscopy, are entirely in reasonable agreement, and they confirm that natural phosphate presented in the formulated E2 matrix (HGEMDA/MDA/PN) has a very effective protective effect. The Bode and phase angle diagrams confirm the results of the electrochemical impedance spectroscopy. Finally, the prediction of the coating behavior is carried out by the semi-empirical PM6 and DFT methods, using the Gaussian software (03), which confirms the adhesion sites of the macromolecular epoxy matrix.

\section{References}

1. Hsissou R, Bekhta A, El Hilal B, et al. Int J Sci Eng Res. 2017;8:1181.

2. Hsissou R, El Rhayam Y, Elharfi A. Int J Innov Appl Stu. 2014;7:674.

3. Dagdag O, Galai M, Touhami ME, et al. J Mater Environ. Sci. 2016;7:3454.

4. Dagdag O, El Gouri M, Galai M, et al. Der Pharma Chemica. 2015;7:114. 
5. Bekhta A, El Allioui TL, Bouih A, et al. Int J Innov Appl Stu. 2014;7:1057.

6. El Hilal B, El Harfi A. Int J Innov Appl Stu. 2014;7:729-735.

7. Hsissou R, Dagdag O, El Harfi A. Mor J Chem. 2015;3:791.

8. Hsissou R, El Harfi A. Mor J Chem. 2016;4:315.

9. Hsissou R, Bekhta A, El Harfi A. J Mater Environ Sci. 2017;8;603.

10. Grich M, Meghraoui H, Ziraoui R, et al. Ann Chim Sci Mat. 2011;36:1.

11. El Azzaoui J, El-Aouni N, Bekhta A, et al. Mor J Chem. 2015;3:338.

12. Gohardani O, Williamson DM, Hammond DW. J Wear. 2012;294-295:336.

13. Hsissou R, Rafik M, Hegazi SE, et al. Arab J Chem Env Res. 2016;3:35.

14. Nakamura Y, Yamaguchi M, Okubo M, et al. J App Polym Sci. 1992;45:1281.

15. Rosales B, Vera R, Morien G. Corros Sci. 1999; 41:625.

16. Cantor A, Bushman J, Glodoski M, et al. Mater Performance. 2006;45:38.

17 Antonijevic MM, Petrovic MB. Int J Electrochem Sci. 2008;3:1.

18. Petitjean J, Aeiyach S, Lacroix JC, et al. J Electroanal Chem. 1999;478:92.

19. Panah NB, Danaee I. Prog Org Coat. 2010;68:214.

20. Ferreira CA, Aeiyach S, Delamar M, et al. Chem Interf Electrochem. 1990;284:351-369.

21. Hsissou R, El Harfi A. Int J Chem Tech Res. 2017;10.

22. Venditti RA, Gillham JK. J Appl Polym Sci. 1997;64:3.

23. Gumen VR, Jones FR, Attwood D. Polymer, 2001;42:5717.

24. Tan TTM, Rode BM. Macromol Theor Simul. 1996;5:467.

25. Tsige M, Taylor PL. Phys Rev. 2002;65.

26. Ulmer CW, Smith DA, Sumpter BG, et al. Comput Theor Polym Sci. 1998;8:311.

27. Mattioni BE, Jurs PC. J Chem Inform, Comput Sci. 2002;42:232.

28. Joyce SJ, Osguthorpe DJ, Padgett JA. J Chem Soc Faraday Trans. 1995;91:2491.

29. Bicerano J. Prediction of polymer properties. New York: Marcel Dekker; 1996.

30. Garcia DR, Julian-Ortiz JV. J Phys Chem B. 2002; 106: 1501.

31. Tao Z, Zhang S, Li W, et al. Ind Eng Chem Res. 2010;49:2593.

32. Emregul KC, Hayvali M. Corros Sci. 2006;48:797.

33. Khaled KF, Babić SK, Hackerman N. Electrochim Acta. 2005;50:2515.

34. Zhu J, Chen S. Int J Electrochem Sci. 2012;7:11884.

35. Elmsellem H, Basbas N, Chetouani A, et al. Port Electrochim Acta. 2014;2:77.

36. Udhayakala P, Rajendiran TV, Gunasekaran S. Chem J Biol Phys SCI A. 2012;2:1151.

37. Elmsellem $H$, Nacer $H$, Halaimia $F$, et al. Int $J$ Electrochem Sci. 2014;9:5328.

38. El Janati A, Kandri RY, Elmsellem H, et al. J Mater Environ Sci. 2016;7:4311.

39. Li W, Hu L, Zhang S, et al. Corros Sci., 2011;53:735.

40. Hammouti B, Dafali A, Touzani R, et al. J Saudi Chem Soc., 2012;16:413.

41. Zubielewicz M, Gnot W. Prog Org Coatings. 2004;49:358. 
42. Rossenbeck B, Ebbinghaus P, Stratmann M, et al. Corros Sci. 2006;48:3703.

43. Liu S, Zhong Y, Jiang R, et al. Corros Sci. 2011;53:746.

44. Ananda KS, Balakrishnan T, Alagar M, et al. Prog Org Coatings. 2006;55:207.

45. Benali O, Larabi L, Traisnel M, et al. Appl Surf Sci. 2007;253:6130.

46. Guillaumin V, Landolt D. Corros Sci. 2002;44:179.

47. Khaled KF, Abdelshafi NS, El-Maghraby A, et al. J Mater Environ Sci. 2011;2:166.

48. Elyoussfi A, Elmsellem H, Dafali A, et al. Der Pharma Chemica. 2015; 7:284-291.

49. Lukovits I, Kalman E, Zucchi F. Corrosion. 2001;57:3.

50. Elmsellem H, Karrouchi K, Aouniti A, et al. Der Pharma Chemica, 2015;7:237.

51. Zhao P, Liang Q, Li Y. Appl Surf Sci. 2005; 252: 1596. 